\title{
A survey of golf injuries in amateur golfers
}

\author{
M. E. Batt MRCGP, Dip Sports Med \\ Royal London Hospital Medical College, London, UK
}

\begin{abstract}
A survey of 461 amateur golfers was undertaken to assess golf injuries. There were 193 respondents of whom $57 \%$ reported injuries. Wrist, back, muscle, elbow and knee problems were the most likely ailments to compromise a player's game. Overuse and poor technique were the main aetiological factors. Attention to those factors in addition to maintenance of physique would reduce the incidence of these problems.
\end{abstract}

Keywords: Golf injuries, amateur golfers, professional golfers

Golf is generally not considered to be a strenuous sport. Nevertheless, golfers do sustain significant injuries, and with the increasing demand for the game $^{1}$ the absolute number of these injuries can be expected to increase. The limited literature on the subject has studied injuries in amateur ${ }^{2,3}$ and professional golfers ${ }^{4}$ and originates principally in the USA.

The purpose of this study was to obtain data on the frequency, type and aetiology of injuries sustained by amateur golfers in the UK. In contrast to previous studies, an attempt was also made to evaluate problems experienced by golfers from ailments not necessarily caused in the first instance by golf, but which now compromise their play.

\section{Subjects and methods}

To obtain data on golfing injuries sustained by amateur golfers in the UK, a survey of an English golf club was undertaken. In all, 461 open-ended questionnaires were sent to the adult playing members of the Royal Worlington and Newmarket Golf Club. The questionnaires were enclosed with annual subscription letters and were circulated to gentleman, lady and university members of the Club.

Replies were received from 193 members $(42 \%)$, of which 164 came from the gentlemen and 29 from the lady members, representing response rates of approximately $41 \%$ and $47 \%$ respectively. The design of the study was such as to allow injuries received while playing golf (termed actual injuries) to be analysed as well as other ailments compromising an individual's golf (termed incidental injuries).

Address for correspondence: Dr M. E. Batt, 39 The High Street, Babraham, Cambridge CB2 4AG, UK

(C) 1992 Butterworth-Heinemann Ltd 0306-3674/92/010063-03

\section{Results}

Replies were received from 193 golfers. Their ages, handicap, experience and amount of play are shown in Table 1.

Male respondents were younger, more experienced, technically more able but played less golf compared with their female counterparts. Injuries (actual and incidental) were reported by $57 \%$ overall, the occurrence among men $(56 \%)$ being marginally lower than in women (59\%). Analyses of actual and incidental injuries are as given in Tables 2 and 3. Actual injuries were reported by $61(32 \%)$ and incidental ailments by $82(42 \%)$ respondents.

Back injuries particularly affected men, and elbow injuries women. Seven $(11 \%)$ of the golfers with actual injuries reported been struck by a club or ball. Back problems were particularly prominent (men $52 \%$, women $29 \%$ ) in those golfers reporting incidental problems. Of incidental ailments, hip problems were associated with an older age group of

Table 1. Questionnaire replies from 193 golfers

\begin{tabular}{|c|c|c|}
\hline & $\underset{(n=164)}{M e n}$ & $\begin{array}{c}\text { Women } \\
(n=29)\end{array}$ \\
\hline Mean (range) age (years) & $49.5(17-85)$ & $53.0(27-83)$ \\
\hline Mean (range) handicap & $14.2(2-24)$ & $23.4(5-36)$ \\
\hline $\begin{array}{l}\text { Mean (range) golf experience } \\
\text { (years) }\end{array}$ & $34.2(4-75)$ & $24.4(2-70)$ \\
\hline $\begin{array}{l}\text { Mean (range) no. of rounds } \\
\text { per month }\end{array}$ & $3.2(0.5-20)$ & $5.3(0.5-12)$ \\
\hline
\end{tabular}

Table 2. Actual injuries ( $n=72$ ) sustained by 61 golfers (site)

\begin{tabular}{lcc}
\hline $\begin{array}{l}\text { Site of } \\
\text { injury }\end{array}$ & $\begin{array}{c}\text { Men } \\
(\mathrm{n}=53)\end{array}$ & $\begin{array}{c}\text { Women } \\
(\mathrm{n}=8)\end{array}$ \\
\hline Wrist & $15(28)$ & $1(12)$ \\
Back & $13(25)$ & \\
Muscular & $6(11)$ & $1(12)$ \\
Elbow & $4(8)$ & $4(50)$ \\
Knee & $4(8)$ & \\
Ankle & $3(6)$ & $2(25)$ \\
Shoulder & $2(4)$ & \\
Hand & $2(4)$ & \\
Neck & $2(4)$ & \\
Foot & $2(4)$ & \\
\hline
\end{tabular}

Values in parentheses are percentages; ${ }^{*}$ others: struck by ball, 6; struck by club, 1; blisters, 2; attacked by bees, 1; laceration, 1 
Table 3. Incidental ailments $(n=82)$ experienced by 82 golfers (site)

\begin{tabular}{lcc}
\hline $\begin{array}{l}\text { Site of } \\
\text { injury* }\end{array}$ & $\begin{array}{c}\text { Men } \\
(\mathrm{n}=65)\end{array}$ & $\begin{array}{c}\text { Women } \\
(\mathrm{n}=17)\end{array}$ \\
\hline Back & $34(52)$ & $5(29)$ \\
Knee & $8(12)$ & $2(12)$ \\
Hip & $6(9)$ & $2(12)$ \\
Elbow & $5(8)$ & $3(18)$ \\
Wrist/hand & $4(6)$ & $3(18)$ \\
Shoulder & $3(5)$ & $1(6)$ \\
Foot & & \\
\hline
\end{tabular}

Values in parentheses are percentages; ${ }^{*}$ others: rheumatoid arthritis, 1; Parkinson's disease, 1; hay fever, 1; angina pectoris, 1 ; amputee, 1 ; polymyalgia rheumatica, 1

golfers. An age analysis of incidental problems is: hip 61.9 years; knee 54.6 years; shoulder 52.5 years; back 49.7 years; and elbow 41.0 years.

The mean age and handicap of male golfers reporting injuries received while playing golf is as given in Table 4. Elbow and wrist injuries occurred in younger (25.6 and 37.5 years, respectively), more able players (handicap averages of 8.6 and 8.3, respectively). The small number of shoulder injuries occurred in older (63.5 years), less able players (handicap average 19.0).

The attributed cause of injuries received (while playing) by male golfers is given in Table 5. This displays aetiology specific to injury and highlights the problems of overuse, incorrect swing and playing conditions. Furthermore, back injuries frequently resulted (six of 13 cases) from causes not directly

Table 4. Mean age and handicaps of golfers injuring themselves during play

\begin{tabular}{lcr}
\hline $\begin{array}{l}\text { Site of } \\
\text { injury }\end{array}$ & $\begin{array}{c}\text { Age } \\
\text { (years) }\end{array}$ & Handicap \\
\hline Wrist & 37.5 & 8.3 \\
Back & 39.6 & 12.0 \\
Muscular & 38.3 & 9.6 \\
Elbow & 25.6 & 8.6 \\
Knee & 35.6 & 17.3 \\
Ankle & 36.0 & 13.0 \\
Shoulder & 63.5 & 19.0 \\
Hand & 46.4 & 13.0 \\
\hline
\end{tabular}

related to the golf swing, e.g. failure to warm up, golf bag, etc. The muscle injuries (tears, strains) were largely caused by trying to hit the ball too hard, and ankle injuries were caused exclusively by tripping.

Data obtained on modality of treatment and length of time away from golf were not sufficiently consistent to warrant analysis.

\section{Discussion}

This study confirms that injuries do occur during the game of golf and also that a variety of physical ailments may hinder the golf swing and compromise play.

The number of previous studies of golfing injuries is limited, making comparisons difficult. In 1988, Jobe and Yocum $^{2}$ reported a study of 412 amateur golfers showing the back as the most common site of injury, followed by the shoulder, elbow and knee. The commonest aetiological factor was overpractice. In 1990, McCarroll et al. ${ }^{3}$ reported on a survey of 4036 amateur golfers, of whom 1144 (28.3\%) replied, reporting the back as the most frequently injured part of the body, followed by the elbow, hand and wrist, shoulder and knee. Excessive play or practice and poor swing mechanics were the most frequently elicited causes of injury. Comparison with the professional side of the game is given by the study of McCarroll and Gioe ${ }^{4}$ in 1982. Tournament professionals suffered from wrist injuries most commonly, followed by injuries to the back, left hand, left shoulder, left knee and left thumb. Overuse (68\%) and contact with other objects were the most frequently reported mechanisms of injury.

The findings of this current study of amateur golfers confirms the high incidence of wrist and back injuries. It found relatively fewer elbow problems, particularly among male golfers. McCarroll et al. ${ }^{3}$ also reported a slightly higher incidence of elbow problems in women than in men. This may reflect biomechanical problems in the golf swing of women related to their greater elbow carrying angle. The high incidence of elbow problems in McCarroll et al's. study of amateurs may relate to overuse because their respondents reported playing an average of eight rounds per month compared with 3.2 rounds by men in this study. Overuse and poor swing mechanics were the causes of elbow injuries in this study.

Table 5. Attributed aetiology of actual injuries (site)

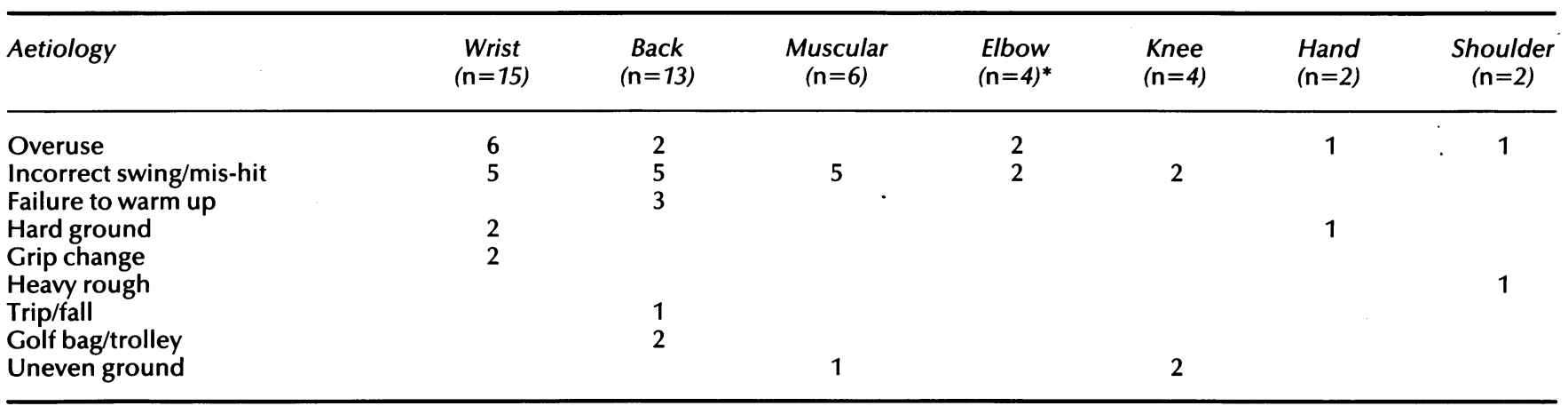

* Golfer's elbow, 2; tennis elbow, 1; avulsion fracture, 1 
Wrist injuries were the most frequent injuries sustained by golfers (particularly men) and occurred in a relatively young (mean age 37.5 years) and able group of golfers (handicap average 8.3). This concurs with McCarroll and Gioe's study of professional golfers which reported wrist injuries occurring most frequently. The mean age of the male professionals was 30 years, and overuse or impact problems were commonly responsible for wrist injuries. A significant number of the wrist injuries in this study occurred in the young male university team golfers. A recent study has shown that golfers with wrist, hand and forearm injuries resulting from golf have excessive wrist motion (especially left) but with reduced mobility and an associated weakness ${ }^{5}$.

The rotator cuff is known to degenerate with age and may be responsible for the finding of shoulder problems in older golfers ${ }^{6}$. The rotator cuff is essential for shoulder stability during the golf swing, and weakness leaves the golfer more prone to injury from overuse and problems at impact, e.g. heavy, rough, hidden obstacles.

Back problems feature highly both in injuries received while playing golf and in ailments compromising golf. It is known that amateur golfers place more stress on their lumbar spines during the golf swing than professionals ${ }^{7}$ and it was therefore not surprising to see a high incidence of back problems in this study. The number of back injuries received while playing could be significantly reduced if players were to warm up appropriately before play and avoid carrying or pulling their golf bags awkwardly.

Overuse and poor swing mechanics were responsible for the vast majority of the injuries occurring during play in this study. An analysis of the mechanism of individual injuries is beyond the scope of this survey but it is clearly the cornerstone in diagnosing, treating and preventing golf injuries. Terrain and weather conditions (e.g. hard ground, heavy rough) are clearly important and technique should be adapted to playing conditions to avoid injury.

A significant number of respondents in this survey have or have had ailments which compromise their golf $(42 \%)$, nearly half $(48 \%)$ of which involve the back. Previous studies have not focused on this aspect of 'golf injuries', but there would seem to be scope for advising golfers on how to cope with their ailments while golfing and thus decrease the probability of perpetuating or aggravating injuries. Back, knee and hip problems were particularly prominent, the last two occurring in the older age group, reflecting degenerative conditions. Chronic lower back ailments are common throughout society and analysis and modification of the golf swing could significantly reduce the stresses placed upon it during golf and thereby reduce further problems.

Avoiding overuse, correcting technique and maintaining reasonable physique will all reduce the incidence of new golf injuries and decrease the disability of other coincident ailments. Seeking an early and accurate diagnosis should help direct appropriate treatment and prevent acute injuries from becoming chronic problems.

\section{References}

1 Royal and Ancient Golf Club of St. Andrew's Development Panel. The Demand for Golf. 1990.

2 Jobe FW, Yocum L. The dark side of practice. Golf 1988; 30: 22.

3 McCarroll JR, Rettig AC, Shelbourne KD. Injuries in the amateur golfer. Phys Sports Med 1990; 18: 122-6.

4 McCarroll JR, Gioe TJ. Professional golfers and the price they pay. Phys Sports Med 1982; 10: 64-70.

5 Cahalan TD, Cooney WP, Tamai K, Chao EYS. Biomechanics of the golf swing in players with pathologic conditions of the forearm, wrist and hand. Am J Sports Med 1991; 19: 288-93.

6 Jobe FW, Perry J, Pink M. Electromyographic shoulder activity in men and women professional golfers. Am J Sports Med 1989; 17; $782-7$.

7 Hosea TM, Gatt CJ, Galli KM, Langrana NA, Zawadsky JP. Biomechanical analysis of the golfer's back. In: Cochran AJ, ed. Science and Golf. London: Chapman and Hall, 1990: 43-8. 